\title{
THROMBUS ASPIRATION WITHOUT STENTING IN A PATIENT WITH ANTERIOR STEMI (REGRESSION AND HEALING OF AN UNSTABLE PLAQUE 24 MONTHS LATER AFTER PCI ASSESSED BY OCT)
}

\author{
Avtandil Babunashvili ${ }^{1}$, Samir Pancholy ${ }^{2}$, Tamara Babunashvili ${ }^{1}$, and Alexander Prohorov ${ }^{3}$ \\ ${ }^{1}$ Center of Endosurgery \\ ${ }^{2}$ Wright Center of Graduate Medical Education \\ ${ }^{3}$ Municipal clinic No7
}

February 9, 2021

\begin{abstract}
We report a case of natural healing of a ruptured unstable coronary plaque using serial OCT examination. Stenting procedure was deferred based on the angiographic and mainly OCT findings. A healing process of ruptured plaque without foreign body was studied using OCT at 3,14 and 24 months after PCI.
\end{abstract}

THROMBUS ASPIRATION WITHOUT STENTING IN A PATIENT WITH ANTERIOR STEMI (REGRESSION AND HEALING OF AN UNSTABLE PLAQUE 24 MONTHS LATER AFTER PCI ASSESSED BY OCT)

\author{
Avtandil Babunashvili*, Samir Pancholy\#, Tamara Babunashvili*, Alexander Prokhorov* \\ * Center of Endosurgery, Moscow, Russian Federation \\ \# Geisinger Commonwealth School of Medicine, The Wright Center for Graduate Medical Education, Scran- \\ ton, PA
}

The work was performed at the Center of Endosurgery

Word count : 3760

Short title : thrombus aspiration without stenting in STEMI ...

Key words : acute myocardial infarction, intravascular visualization, primary PCI, plaque healing

Address for correspondence : 111123, Moscow, Russian Federation, 62 shosse entuziastov. e-mail: avtandil.babunashvili@gmail.com

ABSTRACT: We report a case of natural healing of a ruptured unstable coronary plaque using serial OCT examination. A 41-years old female patient was admitted with anterior STEMI and a thrombus containing ostial LAD lesion. After emergency thrombus aspiration the subsequent stenting procedure was deferred based on the angiographic and mainly OCT findings. A healing process of ruptured plaque without foreign body was studied using OCT at 3, 14 and 24 months after PCI. Endothelization of the ruptured site was found at 3 months and complete healing of vessel wall and reduction of plaque burden with concomitant high-intensity statin therapy occurred after 14 months of the initial procedure. No significant change was 
found between 14 and 24 months. A significant decrease of plaque burden and vessel wall regeneration was determined by OCT in 24 months follow up. In selected cases, OCT-guided PCI in an ACS patient allows us to defer further instrumentation after lumen and flow re-establishment, with adequate natural healing of the ruptured plaque using guideline directed medical therapy.

INTRODUCTION: Atherosclerotic plaque instability and rupture is the underlying pathophysiology for acute coronary syndrome (ACS). Previous autopsy and clinical studies have shown that inflammation and intensive expression of metalloproteinases are key factors for vulnerability of atherosclerotic plaque 11Moreno PR, Falk E, Palacios IF, Newell JB, Fuster V, Fallon JT.Macrophage infiltration in acute coronary syndromes. Implications for plaque rupture. Circulation, 1994, 90: 775-8.'22Zairis MN , Papadaki OA, Manousakis SJ, Thoma MA, Beldekos DJ, Olympios CD, Festeridou CA, Argyrakis SK, Foussas SG. C-Reactive protein and multiple complex coronary artery plaques in patients with primary unstable angina. Atherosclerosis 2002,164: 355-9.. Some pathological studies have shown that ruptured plaques commonly spontaneously heal, and the matrix within healed plaque contains a proteoglycan-rich mass or collagen-rich scar, depending on the healing phase33Burke AP , Kolodgie FD, Farb A, Weber DK, Malcom GT, Smialek J, Virmani R.Healed plaque ruptures and sudden coronary death: Evidence that subclinical rupture has a role in plaque progression.Circulation 2001, 103: 934-40.. Moreover, it is speculated, that repeated silent plaque rupture and subsequent healing results in an increased plaque burden and percent stenosis. Therefore, an understanding of the pathology of healing process is of paramount clinical importance. The healing process of infarct-related plaque has been previously described using pathologic and angioscopic examinations44Eric van Belle, Jean-Marc Lablanche, Christophe Bauters, Natalie Renaud, Eugene P. McFadden, Michel E. Bertrand. Coronary Angioscopic Findings in the InfarctRelated Vessel within 1 month of Acute Myocardial Infarction. Natural History and the effect of Thrombolysis. Circulation 1998, 97: 26-33., with scant data available using high resolution luminal and transmural imaging.

Contrary to angioscopy, new intracoronary visualization modalities - Optical Coherence Tomography (OCT) and Intravascular Ultrasound (IVUS) - allow us a deep insight in vessel wall and plaque to obtain detailed information about plaque structure and tissue composition. Given the high spatial resolution, OCT has been widely used for coronary plaque characterization,55Uemura S, Ishigami K, Soeda T, Okayama S, Sung JH, Nakagawa H, Somekawa S, Takeda Y, Kawata H, Horii M, Saito Y. Thin-cap fibroatheroma and microchannel findings in optical coherence tomography correlate with subsequent progression of coronary atheromatous plaques.Eur Heart J. 2012 Jan;33(1):78-85.'66 Tian J , Ren X, Vergallo R, Xing L, Yu H, Jia H, Soeda T, McNulty I, Hu S, Lee H, Yu B, Jang IK. Distinct morphological features of ruptured culprit plaque for acute coronary events compared to those with silent rupture and thin-cap fibroatheroma: a combined optical coherence tomography and intravascular ultrasound study. J Am Coll Cardiol. 2014 Jun 3;63(21):2209-16. including detection and detailed morphological description of thin-cap fibroatheroma (TCFA) and unstable plaque rupture $77 \mathbf{H u} \mathbf{S}$, Yonetsu T, Jia H, Karanasos A, Aguirre AD, Tian J, Abtahian F, Vergallo R, Soeda T, Lee H, McNulty I, Kato K, Yu B, Mizuno K, Toutouzas K, Stefanadis C, Jang IK. Residual thrombus pattern in patients with ST-segment elevation myocardial infarction caused by plaque erosion versus plaque rupture after successful fibrinolysis: an optical coherence tomography study. J Am Coll Cardiol. 2014 Apr 8;63(13):1336-1338.'88Tearney GJ , Regar E, Akasaka T, Adriaenssens T, Barlis P, Bezerra HG, Bouma B, Bruining N, Cho JM, Chowdhary S, Costa MA, de Silva R, Dijkstra J, Di Mario C, Dudek D, Falk E, Feldman MD, Fitzgerald P, Garcia-Garcia HM, Gonzalo N, Granada JF, Guagliumi G, Holm NR, Honda Y, Ikeno F, Kawasaki M, Kochman J, Koltowski L, Kubo T, Kume T, Kyono H, Lam CC, Lamouche G, Lee DP, Leon MB, Maehara A, Manfrini O, Mintz GS, Mizuno K, Morel MA, Nadkarni S, Okura H, Otake H, Pietrasik A, Prati F, Räber L, Radu MD, Rieber J, Riga M, Rollins A, Rosenberg M, Sirbu V, Serruys PW, Shimada K, Shinke T, Shite J, Siegel E, Sonoda S, Suter M, Takarada S, Tanaka A, Terashima M, Thim T, Uemura S, Ughi GJ, van Beusekom HM, van der Steen AF, van Es GA, van Soest G, Virmani R, Waxman S, Weissman NJ, Weisz G; International Working Group for Intravascular Optical Coherence Tomography (IWG-IVOCT).Consensus standards for acquisition, measurement, and reporting of intravascular optical coherence tomography studies: a report 
from the International Working Group for Intravascular Optical Coherence Tomography Standardization and Validation.J Am Coll Cardiol. 2012 Mar 20;59(12):1058-72.. Nevertheless, scant data is available on the natural course of a ruptured plaque leading to acute coronary syndrome. Rioufol G. et al have used IVUS to demonstrate the evolution and healing process of spontaneously ruptured atherosclerotic plaque. The authors evaluated 28 ruptured plaques in 14 patients99Rioufol G, Gilard M, Finet G, Ginon I, Boschat J, André-Fouët X. Evolution of spontaneous atherosclerotic plaque rupture with medical therapy: long-term follow-up with intravascular ultrasound. Circulation. 2004 Nov 2;110(18):2875-80.. According to the study findings, only half of the ruptured plaques were healed, and the remodeling index was unchanged or considerably positive with a trend towards reduction of plaque burden.

It is not known how ruptured plaque and vessel wall at the site of the culprit lesion evolve in the follow up period. This raises concerns about treatment issues in terms of the associated risk of thrombosis. While angioscopy data confirm the presence of thrombus on the culprit lesion after six months and even up to 18 months1010Y. Ueda, M. Asakura, O. Yamaguchi, A. Hirayama, M. Hori, K. Kodama.The Healing Process of Infarct-Related Plaques. Insight of 18 Months of Serial Angioscopic Follow-up. JACC 2001, 38, 7: 1916-22., late (18-24 months) follow up is necessary for studying the natural history of atherothrombosis.

We describe the natural course of ruptured plaque causing an anterior STEMI, treated without balloon dilatation or stent placement, using OCT examination over a 24-month follow up. To the best of our knowledge, this is the first description of the healing process of a ruptured plaque in vivo by OCT.

CASE PRESENTATION: A 41-years old female patient was admitted with anterior STEMI diagnosis 2.5 hours after symptom onset. Taking into consideration the ECG changes (ST elevation in I, aVL, and $\mathrm{V}_{2}-\mathrm{V}_{6}$ leads) and increased Troponin I level on presentation (more than 15 times the upper limit of normal), emergency cardiac catheterization was initiated. After intravenous heparin administration $(70 \mathrm{U} / \mathrm{kg})$ coronary arteriography was done through the distal right radial access. Angiography revealed single vessel disease with a thrombus containing lesion at the ostium of the left anterior descending (LAD) artery (Fig. $1)$.

Taking into account large thrombus burden (Thrombus burden grade $(\mathrm{G})>2 \mathrm{X}$ Reference vessel diameter (RVD)1111Sianos G, Papafaklis MI, Serruys PW. Angiographic thrombus burden classification in patients with ST-segment elevation myocardial infarction treated with percutaneous coronary intervention . J Invasive Cardiol. 2010 Oct;22(10 Suppl B):6B-14B.) thrombus aspiration procedure was performed using a $6 \mathrm{~F}$ ELIMINATE catheter (Terumo corporation, Japan) with good immediate result (Fig. 2A). Control angiography revealed complete disappearance of the filling defect from vessel lumen, nonsignificant residual stenosis (minimal lumen diameter by $\mathrm{QCA}=3.23 \mathrm{~mm}$ ) and antegrade TIMI III flow. A $\mathrm{IIb} /$ IIIa inhibitor agent eptifibatide (Integrillin) was administered and control OCT was performed thereafter. OCT revealed arterial lumen without thrombotic mass and clear signs of a ruptured unstable plaque with disruption of fibrous cap (defect size was 3.7 X $1.2 \mathrm{~mm}$ ) overlaying a large necrotic core (Fig. 2B). The plaque extended into the proximal part of left anterior descending artery (LAD) without involvement of its ostium and occupied nearly half of the lumen circumference $\left(173.8^{\circ}\right)$. 3D reconstruction image showed localization and size of ruptured area in LAD lumen and its 3D dimensional orientation to the circumflex artery ostium (Fig. 2C). Mean Luminal Diameter (MLD) at the rupture site by OCT measurement was $3.2 \mathrm{~mm}$ (vessel distal reference diameter $(\mathrm{VRD})=3.8 \mathrm{~mm}$ ) and minimal lumen cross sectional area (CSA) 7.9 $\mathrm{mm}^{2}$ (distal reference CSA $-8.6 \mathrm{~mm}^{2}$ ). Therefore, area stenosis calculated as distal reference CSA - minimal lumen CSA/ distal reference CSA was $9 \%$. Taking into account the geometry of the vessel lumen, absence of a thrombotic mass at the plaque rupture site and antegrade TIMI III flow, we decided not to implant stent. In postintervention period DAPT was continued and the patient was discharged 10 days after initial admission. Due to hypercholesterolemia (cholesterol $6.25 \mathrm{mmol} / \mathrm{l}, \mathrm{LDL}=3.85 \mathrm{mmol} / \mathrm{l}$ ) high-intensity statin therapy (Rosuvastatin 40mg once daily) was prescribed.

After 3 months, control angiography shown good patency of LAD and the arterial lumen at the site of plaque rupture remained without restenosis (Fig. 3A). OCT revealed clear signs of an ongoing healing process of 
previously ruptured plaque with fibrotic transformation of the plaque, and a thin layered neointima (90-110 microns) covering its surface. Plaque burden decreased, but residual necrotic core still persisted (Fig. 3B). Minimal lumen CSA was $5,97 \mathrm{~mm}^{2}$. Despite the thin neointima covering the ruptured plaque surface, DAPT was continued for 12 months as recommended by the guidelines.

Angiography at 14 months revealed no restenosis (Fig. 4A). OCT examination showed complete healing of vessel wall at the site of previous plaque rupture. Plaque burden was significantly decreased and transformed into a small sized stable fibrotic plaque (Fig. 4B). Minimal lumen CSA was $8,2 \mathrm{~mm}^{2}$, vessel wall CSA at the point of minimal lumen CSA was $10.5 \mathrm{~mm}^{2}$. Percent atheroma volume (PAV) and total atheroma volume (TAV) calculated as previously described1212Bill D Gogas, Vasim Farooq, Patrick W Serruys, Hector M Garcìa-Garcìa. Assessment of coronary atherosclerosis by IVUS and IVUS-based imaging modalities: progression and regression studies, tissue composition and beyond. Int $J$ Cardiovasc Imaging, $2011 \mathrm{Feb} ; 27(2): 225-37$. were $21.9 \%$ and $27.3 \mathrm{~mm}^{3}$ respectively. At 12 months follow up patient had stopped DAPT, continued lipid lowering therapy and achieved guideline recommended target LDL and HDL levels.

24 months after initial procedure patient was admitted due to recurrent angina. Control angiography shown no restenosis in LAD ostium at the site of thrombus aspiration of without stenting (Fig. 5A) and new lesion in RCA, which was stented successfully. Repeat OCT evaluation of LAD ostium revealed stable thick cap fibrotic plaque without lipid core (Fig. 5, b) occupying $115^{\circ}$ (approximately 33\%) of lumen circumference. No significant vessel wall remodeling occurred in period between 14 and 24 months after primary PCI. Minimal lumen CSA and vessel wall CSA at the site of previous plaque rupture were $8.6 \mathrm{~mm}^{2}$ and 11.0 $\mathrm{mm}^{2}$. Calculated PAV and TAV were $21.8 \%$ and $23.5 \mathrm{~mm}^{3}$ respectively.

DISCUSSION: We describe the natural course of an unstable, ruptured plaque presenting as a STEMI, treated without subsequent mechanical angioplasty (instrumentation of the plaque) or stenting. Although the acute phase of the unstable plaque rupture is described comprehensively1313Jacob Fog Bentzon , Fumiyuki Otsuka, Renu Virmani, Erling Falk. Mechanism of plaque formation and rupture. Circ Res, 2014, 114: 1852-1866., the chronic phase or healing process of ruptured plaque has not been well defined in a live patient. Many studies describe dynamic changes of atherosclerotic plaque volume and composition using statin therapy and subsequent serial IVUS visualization1414H. Daida, T. Dohi, Y. Fukushima, H. Ohmura and K. Miyauchi. The Goal of achieving atherosclerotic plaque regression with lipid-lowering therapy: Insights from IVUS trials. J Atheroscler Thromb, 2019, 26: 592-600.1515M. Hartmann , J. Huisman, D. Bose, LO. Jensen, P. Schoenhagen, GS. Mintz, R. Erbel and C. von Birgelen. Serial Intravascular Ultrasound assessment of changes in coronary atherosclerotic plaque dimensions and composition: an update. Eur J of Echocardiography, 2011, 12: 313-321.'1616K. Hattori , Y. Ozaki, TF. Ismail, M. Okumura, H. Naruse, Sh. Kan, M. Ishikawa, T. Kawai, M. Ohta, H. Kawai, T. Hashimoto, Y. Takagi, J. Ishii, PW. Serruys, J. Narula. Impact of statin therapy on plaque characteristic as assessed by serial OCT, Grayscale and Integrated Backscatter-IVUS.JACC: Cardiovasc Imaging, 2012, 5(2): 169-77. even in ACS patients ${ }^{9}$, but none of them report changes and healing process of the ruptured unstable plaque using a high-resolution imaging modality such as OCT examination.

The role of plaque healing process in stenosis formation and progression has been determined in previous studies. Burke AP et al proposed that scar-like contraction of the healing fibrous tissue may be a cause of the negative remodeling often seen in severely stenosed arterial lumen ${ }^{3}$. Some authors indicate the silent plaque rupture and subsequent healing as a major mechanism for plaque growth and chronic stenosis formation1717C. Bauters .Silent coronary plaque rupture. Archives of cardiovascular diseases, 2008, 101: 79-80.. This suggestion is based on multilayered plaque appearance consistent with a history of incorporation of organized thrombus formed on ruptured or eroded plaque $^{3}$.

Minimal positive remodeling of vessel lumen was detected in our case between 16 and 24 months of follow up period. Complete endothelization of a ruptured plaque occurred 3 months after initial PCI, but residual mass of necrotic core was still observed. Moreover, significant regression of a plaque burden was confirmed by OCT up to 24 months after coronary intervention and concomitant high-intensity lipid lowering therapy. No 
significant changes were noted in plaque burden, atheroma composition, vascular geometry and atheroma percent or total volume between 12 and 24 months after PCI. This could imply that at 12 months, the ruptured plaque had stabilized and did not change significantly morphologically in the subsequent period. Interestingly, the classical three-layered OCT sign of the arterial wall appeared in follow up accompanied by the process of atherosclerotic plaque regression.

Several studies have shown that lipid lowering therapy with statins is associated with plaque stabilization and a considerable number of studies demonstrated plaque regression with statins or non-statin lipid lowering therapy1818M. Banach, C. Serban, A. Sahebkar, DP. Mikhailidis, S. Ursoniu, KK. Ray, J. Rysz, PP. Toth, P. Muntner, S. Mosteoru, HM. Garcia-Garcia, G. Kees Hovingh, JJP. Kastelein, PW. Serruys and Lipid and Blood Pressure Meta-analysis Collaboration (LBPMC) Group. Impact of Statin Therapy on Coronary Plaque Composition: a systematic review and meta-analysis of virtual histology intravascular ultrasound studies. BMC Medicine 2015, 13: 229-49.'1919X. Tang, Y. Yang, S. Luo, Y. Zhao, C. Lu, Y. Luo, F. Zhang, H. Xiao. The effect of Statin Therapy on Plaque Regression following Acute Coronary Syndrome: a meta-analysis of prospective trials. Coronary Artery Disease, 2016, 27 (8): 636-49.. However, in all these studies IVUS was used as the only intravascular visualization technique for measuring the atheroma percent or total volume changes in the follow up period, as well as for assessment of plaque composition changes. Some authors studied the plaque healing process using OCT examination ${ }^{16}$ but in published articles using both imaging modalities only non-culprit segments were included in the analysis2020R. Vergallo, I. Porto, D. D'Amario, G. Anniballi, M. Galli, S. Benenati, F. Bendandi, F. Fracassi, C. Aurigemma, AM. Leone, A. Buffon, F. Burzotta, C. Trani, G. Niccoli, G. Liuzzo, F. Prati, V. Fuster, I-K. Jang, F. Crea.Coronary Atherosclerosis Phenotype and Plaque Healing in Patients with Reccurent Coronary Syndromes compared with Patients with Long-term Clinical Stability. An in Vivo Optical Coherence Tomography Study. JAMA Cardiol, 2019, 4(4): 321-9.. Therefore, characteristics of the healing process of a clinically manifested ruptured unstable plaque in vivo remained unknown. To our best knowledge, this is a first report of the serial OCT examination for detailed in vivo assessment of the plaque regression and a vessel wall regeneration up to 24 months after initial primary PCI without plaque/stenosis dilatation or stenting.

The guidelines recommend delayed or immediate coronary stenting as a preferable option compared to balloon angioplasty alone in patients with STEMI2121F-J Neumann, M. Sousa-Uva, A. Ahlsson, F. Alfonso, AP. Banning, U. Benedetto, RA. Byrne, JP. Collet, V. Falk, SJ. Head, P. Juni, A. Kastrati, A. Koller, SD. Kristensen, J. Niebauer. DJ. Richter, PM. Seferovic, D. Sibbing, GG. Stefanini, S. Windecker, R. Yadav, MO. Zembala. 2018 ESC/EACTS guidelines on myocardial revascularization. Eur Heart J 2019, 40: 87-165.. Several previous studies have investigated deferred stenting procedure as an option to preserve microcirculation option with conflicting results2222Carrick D, Oldroid KG, McEntegart M, Haig C, Petrie MC, Eteiba H, Hood S, Owens C, Watkins S, Layland J, Lindsay M, Peat E, Rae A, Behan M, Sood A, Hillis WS, Mordi I, Mahrous A, Ahmed N, Wilson R, Lasalle L, Genereux P, Ford I, Berry C. A randomized trial of deferred stenting versus immediate stenting to prevent no- or slow-reflow in acute ST-segment elevation myocardial infarction (DEFER-STEMI). J Am Coll Cardiol 2014; 63: 2088-2098.2323Belle L , Motreff P, Mangin L, Range G, Marcaggi X, Marie A, Ferrier N, Dubreuil O, Zemour G, Souteyrand G, Caussin C, Amabile N, Isaaz K, Dauphin R, Koning R, Robin C, Faurie B, Bonello L, Champin S, Delhaye C, Cuilleret F, Mewton N, Genty C, Viallon M, Bosson JL, Croisille P.MIMI Investigators. Comparison of immediate with delayed stenting using the Minimalist Immediate Mechanical Intervention approach in acute ST-segment-elevation myocardial infarction: The MIMI study. Circ Cardiovasc Interv 2016;9:e003388.. The large (deferred vs conventional stent implantation) multicenter DANAMI 3-DEFER trial showed no statistically significant difference in the primary clinical outcome between groups in the follow-up period2424Kelbaek H Hofsten DE, Kober L, Helqvist S, Klovgaard L, Holmvang L, Jorgensen E, Pedersen F, Saunamaki K, De Backer O, Bang LE, Kofoed KF, Lonborg J, Ahtarovski K, Vejlstrup N, Botker HE, Terkelsen CJ, Christiansen EH, Ravkilde J, Tilsted HH, Villadsen AB, Aaroe J, Jensen SE, Raungaard B, Jensen LO, Clemmensen P, Grande P, Madsen JK, Torp-Pedersen C, Engstrom T. Deferred versus conventional stent implantation in patients with ST-segment 
elevation myocardial infarction (DANAMI 3-DEFER): An open-label, randomized controlled trial. Lancet 2016;387:2199-2206.. Moreover, the results of two landmark RCTs suggest that the routine use of thrombus aspiration is not indicated 2525Frobert $\mathbf{O}$, Lagerqvist B, Olivecrona GK, Omerovic E, Gudnason T, Maeng M, Aasa M, Angeras O, Calais F, Danielewicz M, Erlinge D, Hellsten L, Jensen U, Johansson AC, Karegren A, Nilsson J, Robertson L, Sandhall L, Sjögren I, Ostlund O, Harnek J, James SK: TASTE Trial. Thrombus aspiration during ST-elevation myocardial infarction. N Engl J Med. 2013 Oct 24; 369(17):1587-97.'2626Jolly SS , Cairns JA, Yusuf S, Meeks B, Pogue J, Rokoss MJ, Kedev S, Thabane L, Stankovic G, Moreno R, Gershlick A, Chowdhary S, Lavi S, Niemelä K, Steg PG, Bernat I, Xu Y, Cantor WJ, Overgaard CB, Naber CK, Cheema AN, Welsh RC, Bertrand OF, Avezum A, Bhindi R, Pancholy S, Rao SV, Natarajan MK, ten Berg JM, Shestakovska O, Gao P, Widimsky P, Dzavík V; TOTAL Investigators. Randomized trial of primary PCI with or without routine manual thrombectomy. N Engl J Med. 2015 Apr 9; 372(15):1389-98.Legends:Fig.1: Initial arteriography revealed single vessel disease and a thrombus containing lesion at the LAD ostium (arrow).Fig. 2: Angiography and OCT immediately after Interventional procedure: a - arteriography after thrombus aspiration shows vessel lumen with minimal residual stenosis ("stent-like" result) and no signs of a thrombotic mass (arrow). b - OCT examination after thrombus aspiration demonstrated unstable plaque with a large necrotic core (NC) and ruptured fibrotic cap (arrow). No concomitant thrombus seen along a ruptured plaque. $\mathrm{c}-3 \mathrm{D}$ reconstruction of the ruptured plaque area allows to see location of a rupture in LAD lumen (arrow) and its relation to the CxA ostium.Fig. 3: Control angiography and OCT examination after 3 months of the initial PCI procedure: a - no restenosis was detected in LAD by angiography at the site of previous thrombus aspiration without stenting (arrow); b - OCT examination shown complete endothelization of a previously ruptured plaque surface (arrows), but residual necrotic core of the plaque still persisted (marked by an asterisk).Fig. 4: 14 months follow up result assessed by angiography and OCT: a - control angiography shows LAD without restenosis after initial intervention (arrow). b - OCT picture revealed small fibrotic plaque (asterisk) at the site of previously unstable and ruptured plaque.Fig. 5: Control arteriography and OCT of the LAD 24 months later: a - LAD without restenosis after primary coronary intervention (arrow). b - Small stable plaque (asterisk) detected by OCT without significant changes in plaque size and tissue composition compared to 14-month follow up result. Classic 3-layered structure of the vessel wall is clearly visible (media signed by arrows).. Nevertheless, in the high-thrombus burden subgroup mitigation of the risk of microembolization and no-reflow provides a rationale for "bail-out" thrombus aspiration procedure. No doubt, that coronary stenting is the technique of choice during primary PCI in patients with STEMI, however, main question that arises following the described case is, can we safely defer stent implantation in STEMI patient? if yes, in which particular situation can we leave culprit lesion without a stent? Logically, vessel wall healing process without a foreign body (as a trigger of inflammation) could be closer to physiology and therefore preferable. This case shows the potential of OCT based "stent-free" strategy with concomitant dual antiplatelet and high-intensity statin therapy to obtain a satisfactory short-term and long-term result. Another important point is duration of dual antiplatelet therapy (DAPT) after initial PCI in ACS patients. Taking into account the complete endothelization of ruptured plaque after 3 months, is this OCT finding sufficient basis for shorter DAPT? This case also highlights the utility of OCT imaging in studying the natural healing process after a ruptured plaque event leading to a major clinically relevant presentation.

CONCLUSION : In selected cases the OCT-based "stent-free" strategy of primary PCI may be useful to obtain short- and long term satisfactory result in patients with STEMI. Supposedly, this approach promotes the natural healing of ruptured plaque and vessel wall without permanent foreign body in the arterial lumen.

\section{ACKNOWLEDGMENT}

We wish to thank all the nurses and technicians of our catheterization laboratory for their professional contribution and help. We also would like to express our appreciation to the technical personnel of the Terumo company for their involvement in this study. 


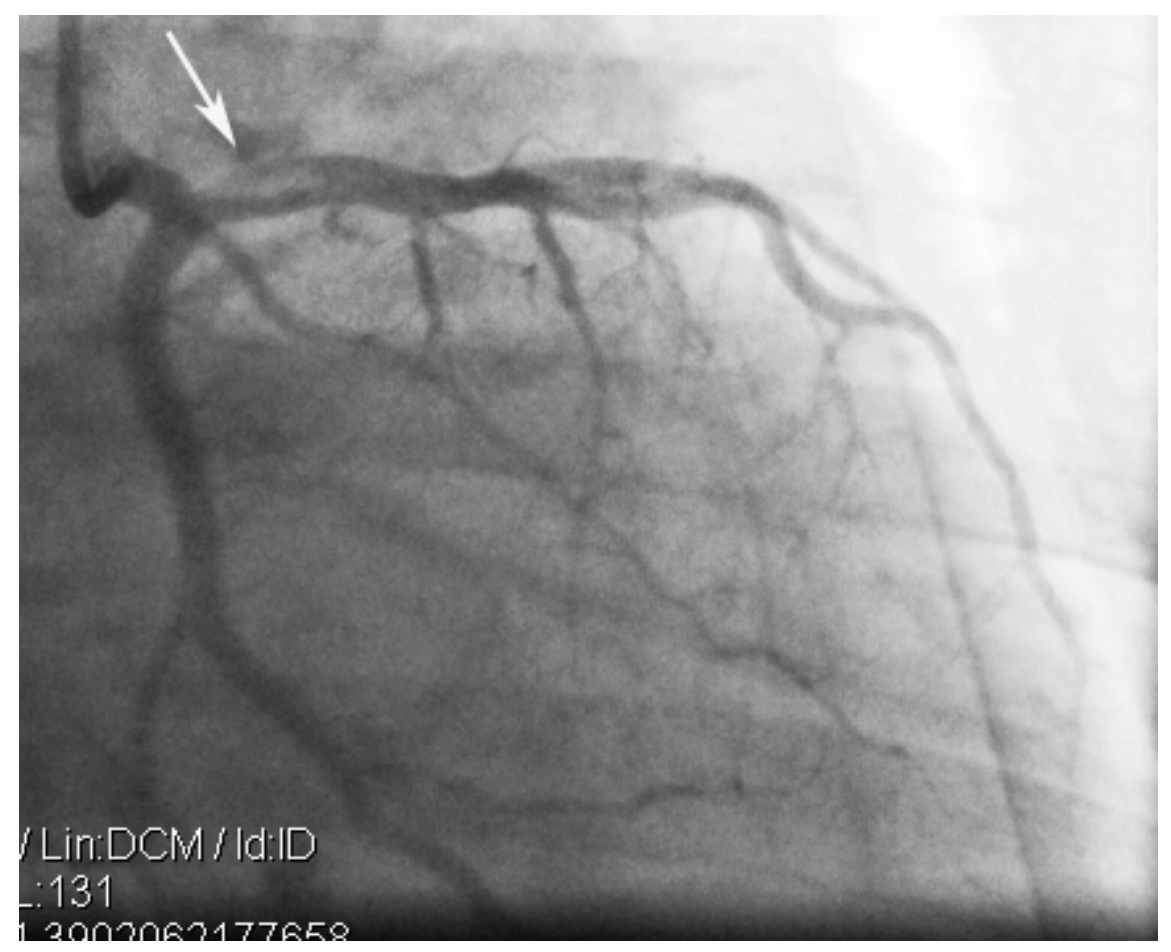



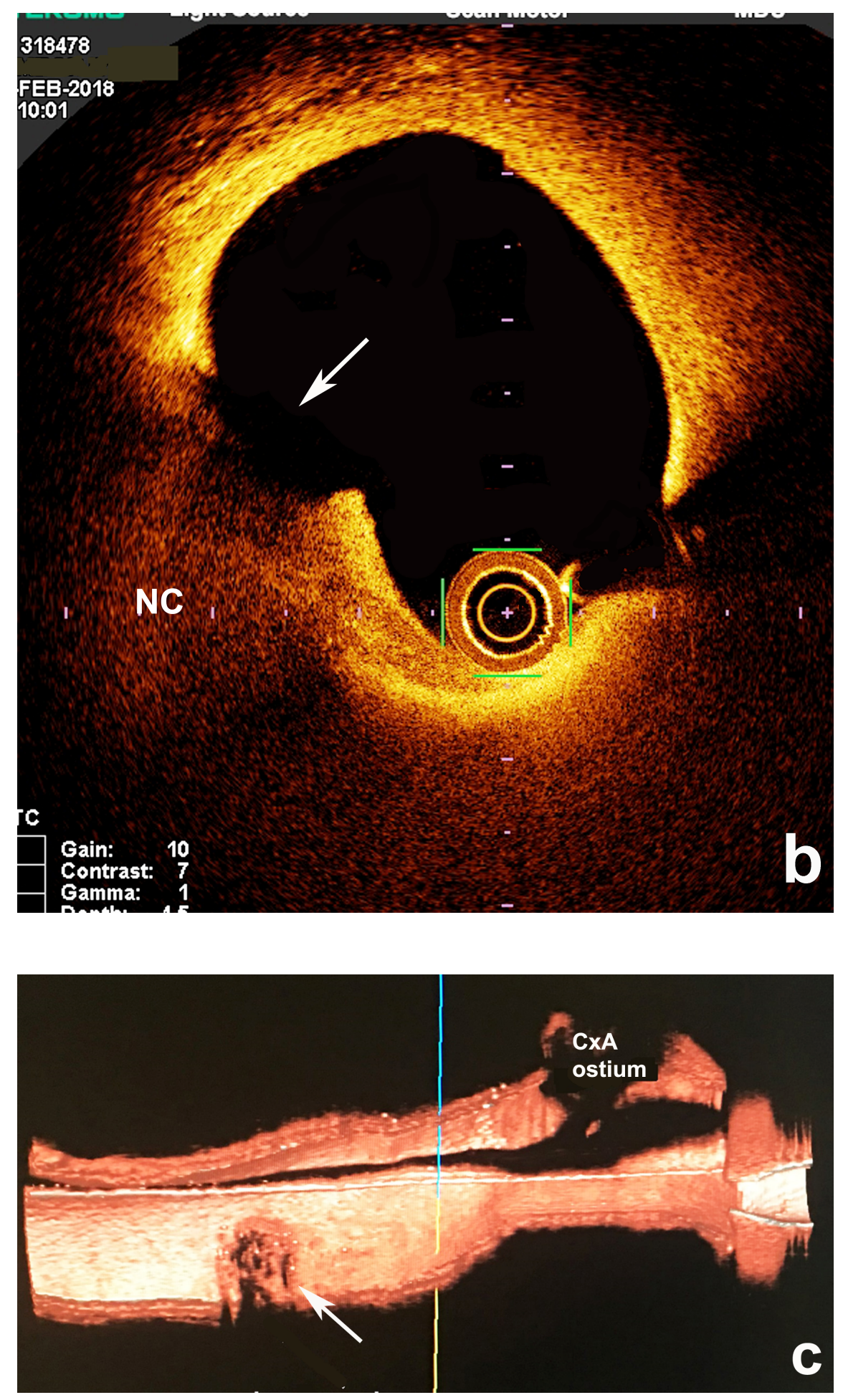
$1 \%$

1//4 (F) $14 / / 4$ )

g. $10 x$

\section{For Trro 11.3.}

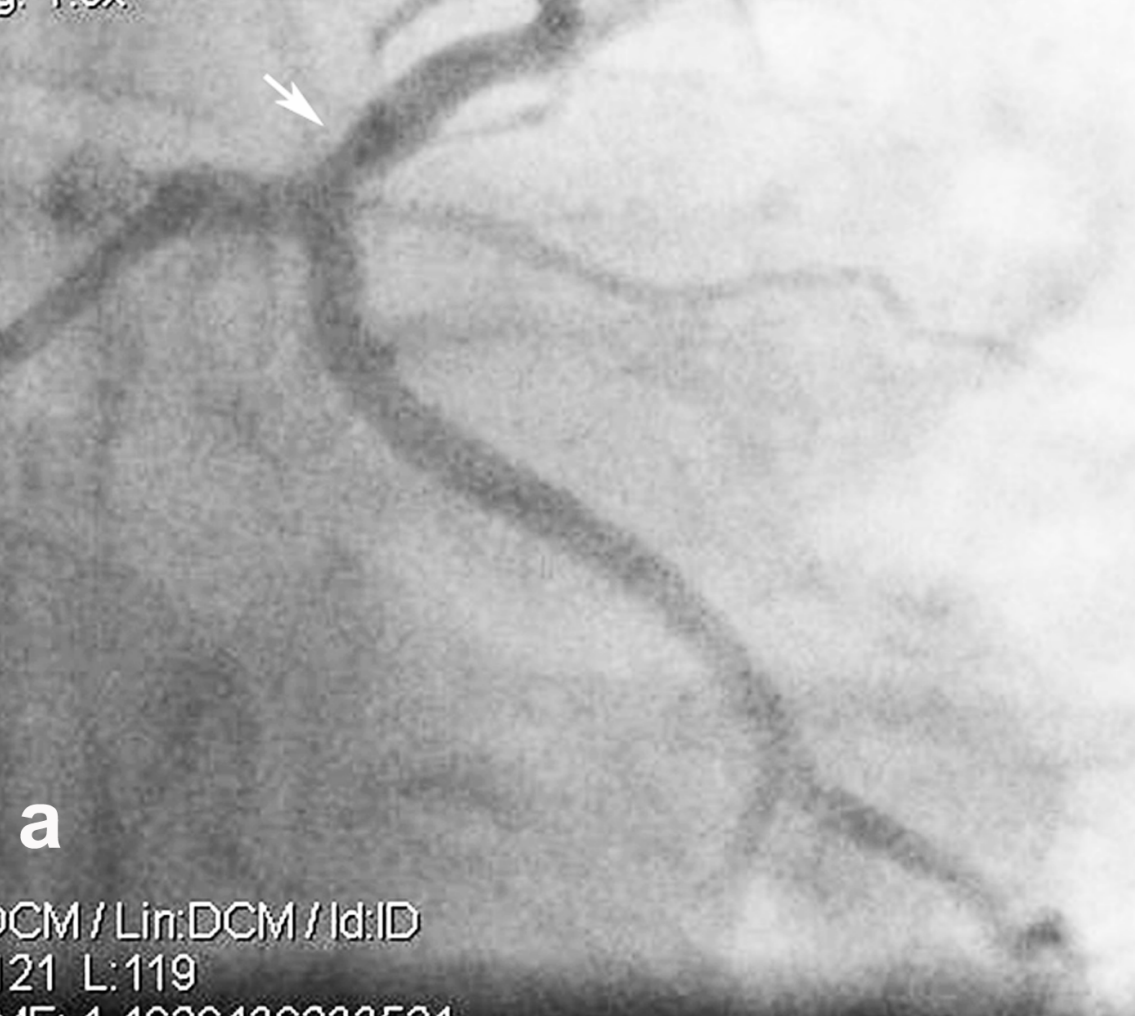




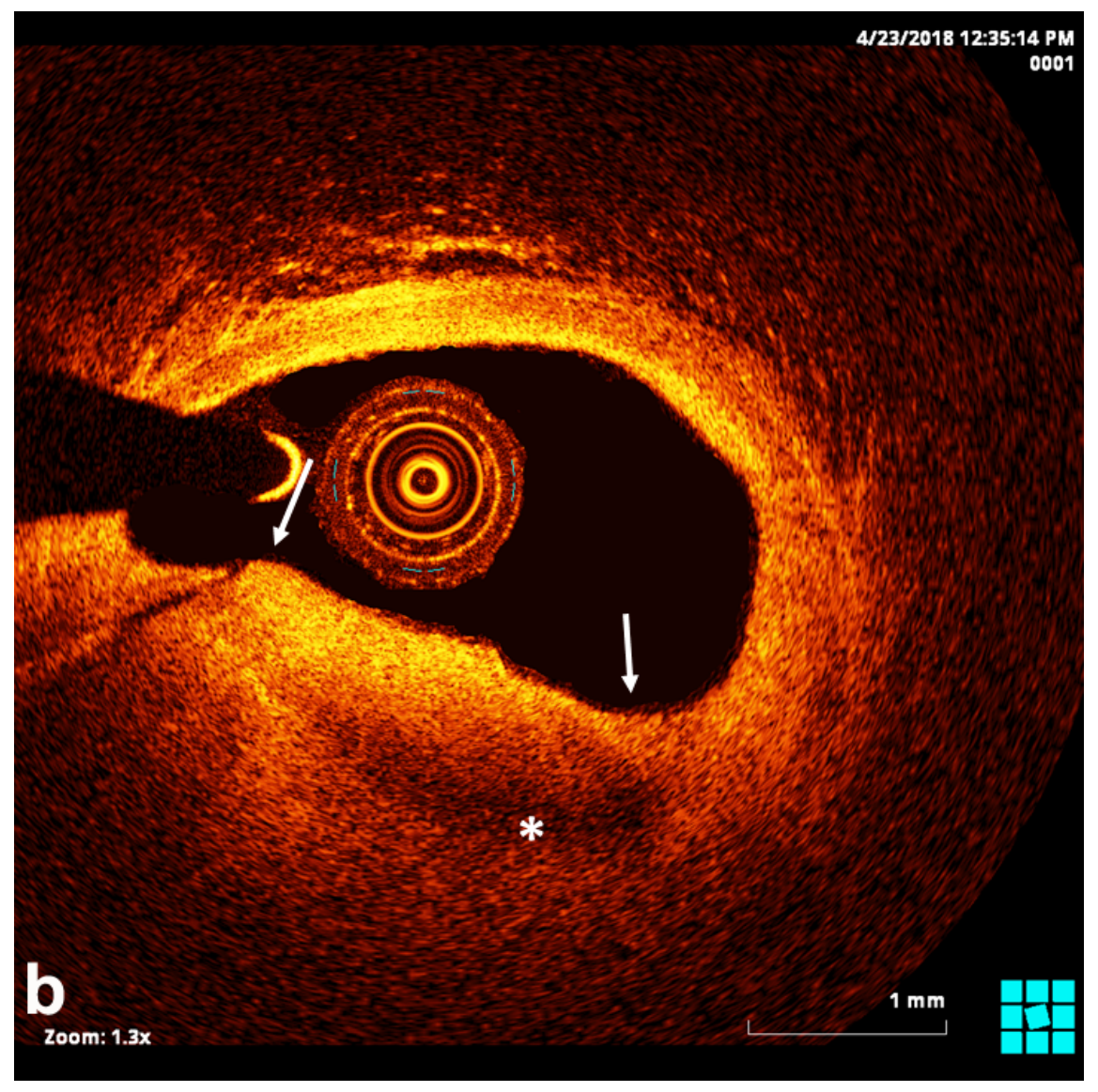




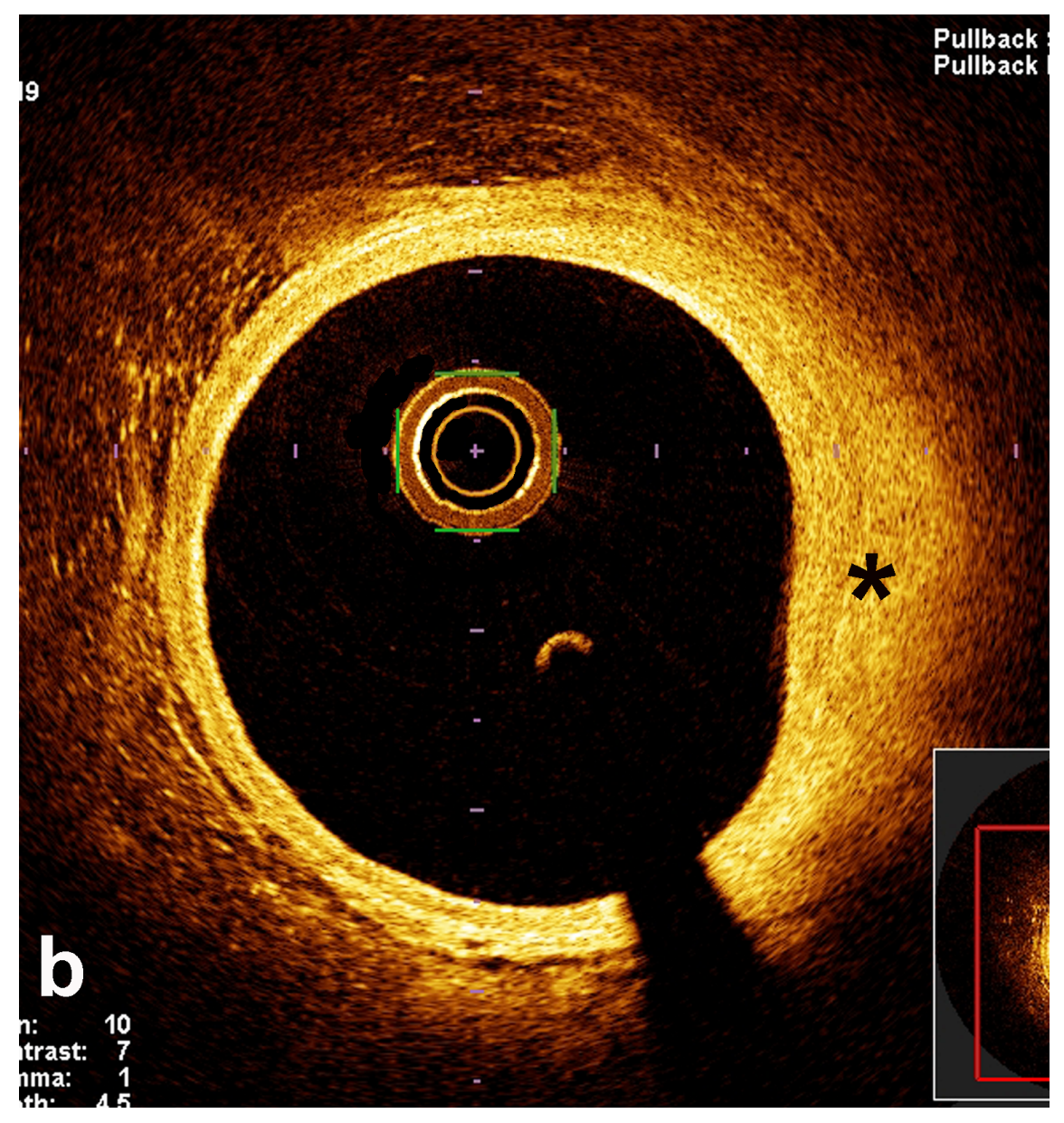




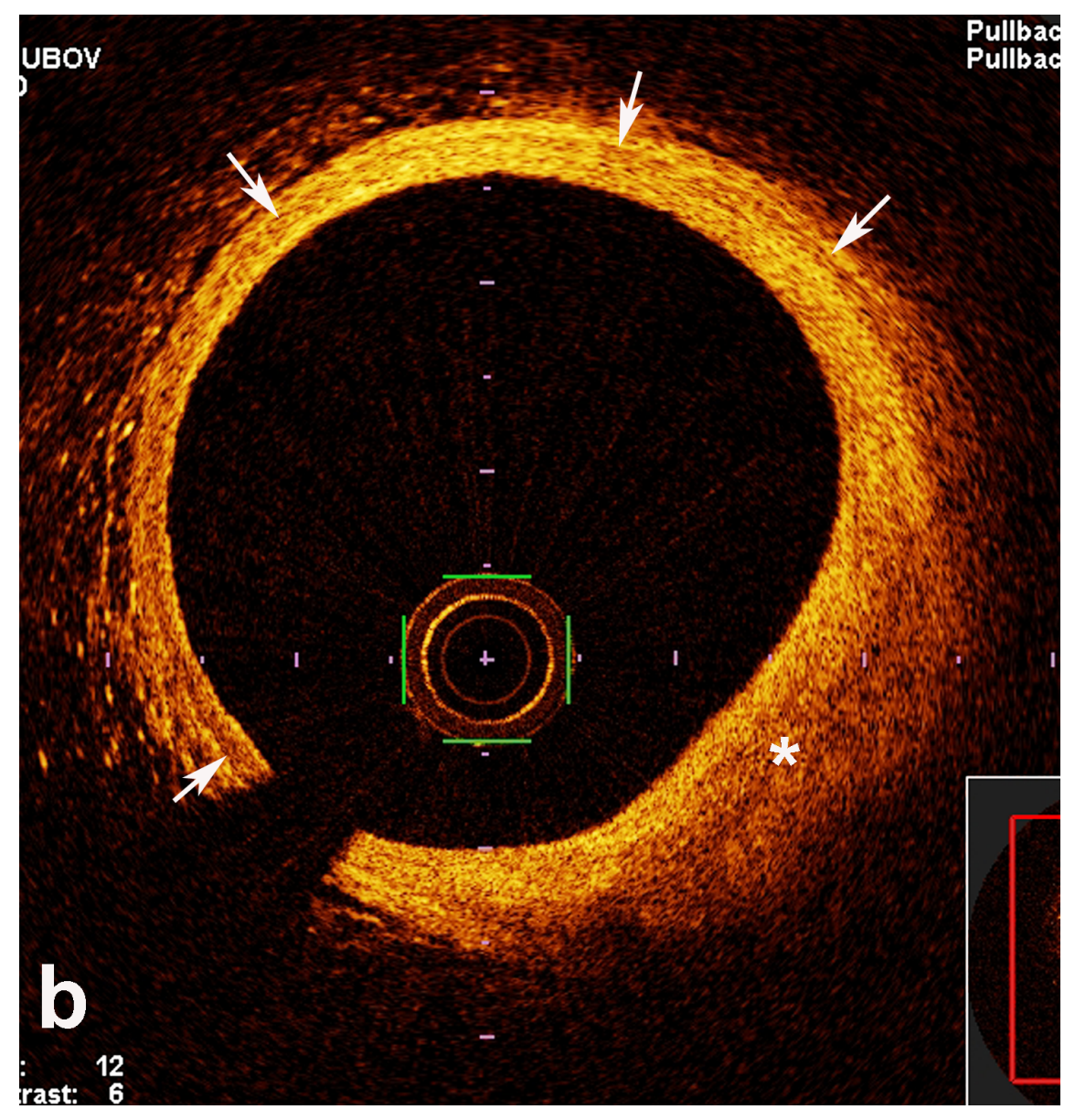

